\title{
Alchornea Cordifolia (Christmas Bush) Leaves Extract Shows Activity Against Extended-Spectrum Beta-Lactamase-Producing Klebsiella Pneumoniae That Cause Multi-Drug Resistant Urinary Tract Infections
}

\author{
Henry Kwadwo Hackman ${ }^{1 *}$, Lawrence Annison ${ }^{1}$, Reuben Essel Arhin ${ }^{2}$, Bright Kojo Azumah ${ }^{2}$, David Boateng ${ }^{2}$, \\ Blessing Nwosu ${ }^{2}$, Mark Appenteng ${ }^{3}$ \\ *1. Henry Kwadwo Hackman (Corresponding Author) \\ 1. Accra Technical University, Faculty of Applied Sciences \\ Department of Medical Laboratory Technology, P. O. Box GP 561, Accra, Ghana \\ 2.Accra Technical University, Faculty of Applied Sciences \\ Department of Science Laboratory Technology, P. O. Box GP 561, Accra, Ghana \\ 3.Centre for Plant Medicine Research (CPMR), Mampong-Akuapim, Ghana
}

\begin{abstract}
Klebsiella pneumoniae are one of the most common cause of multi-drug resistant urinary tract infections such as cystitis and pyelonephritis. Extended-spectrum beta-lactamases are plasmid-mediated enzymes commonly found in the Klebsiella pneumoniae and other Gram negative bacteria. They are capable of hydrolysing beta-lactams except carbapenems and cephamycins. Extended-spectrum beta-lactamases also confer resistance to several nonbeta-lactam antibiotics, limiting treatment options for urinary tract infections caused by extended-spectrum betalactamases -producing $K$. pneumoniae. This study determined the in vitro efficacy of Alchornea cordifolia on extended-spectrum beta-lactamases -producing $K$. pneumoniae. Serial dilutions of the ethanolic extract of the leaves were prepared and tested against the extended-spectrum-beta-lactamases-producing K. pneumoniae. The phytochemical screening was performed to determine the antibacterial compounds. The Christmas bush leaves extracts concentrations ranging from $50 \mathrm{mg} / \mathrm{ml}-200 \mathrm{mg} / \mathrm{ml}$ showed significant active diameter zone of inhibition. The ethanolic extract of $A$. cordifolia leaves had minimum inhibition concentration and minimum bactericidal concentration of $3.13 \mathrm{mg} / \mathrm{ml}$ indicating significant antibiotic activity against the ESBL isolates. The phytochemical screening of the Christmas bush leaves showed the presence of antimicrobial phytochemicals such as flavonoids. Ethanolic extracts of Christmas bush leaves is proving to be efficacious against multi-drug resistant urinary tract infections. This offers hope for the development of effective antibiotics due to the presence of flavonoids in the $A$. cordifolia leaf extracts. Therefore, there is the need to determine the toxicological effect and clinical trials of the active antimicrobial compounds isolated in the leaf extracts of $A$. cordifolia shrub.
\end{abstract}

Keywords: Alchornea. cordifolia, Flavonoids, Multi-drug resistant, Extended-spectrum beta-lactamase, Klebsiella pneumoniae

DOI: $10.7176 / \mathrm{JNSR} / 11-24-03$

Publication date: December $31^{\text {st }} 2020$

\subsection{Introduction}

Extended-spectrum beta-lactamases (ESBLs) are plasmid-mediated beta lactamases that are capable of hydrolysing beta-lactams except carbapenems and cephamycins. They are inhibited by beta-lactamase inhibitors such as clavulanic acid, sulbactam and tazobactam. They have been found in the Enterobacteriaceae and other Gram negative bacilli. ESBL producing isolates are predominantly Klebsiella pneumoniae and Escherichia coli (Paterson and Bonomo, 2005).

Klebsiella pneumoniae are inhabitants of the intestinal flora and are among the most common causes of urinary tract infections such as cystitis (bladder infection) and pyelonephritis (kidney infection). It is estimated that about 150 million people develop urinary tract infection in every given year (Flores-Mireles et al.,2015) and are more common in women than men (Salvatore et al., 2011). Enterobacteriaceae are the source of community and hospital acquired infections. Because ESBL enzymes are plasmid mediated, the genes encoding these enzymes are easily transferable among different bacteria. Most of these plasmids not only contain DNA encoding ESBL but also carry genes conferring resistance to several non-beta-lactam antibiotics (Nordmann et al., 2011). Consequently, most ESBL isolates are not only resistant to penicillins, cephalosporins and monobactams but also to other classes of antibiotics including aminoglycosides, fluoroquinolones, tetracyclines, nitrofurantoin and sulfamethoxazole-trimethoprim.

Since 2000, spread of community acquired enterobacterial isolates (Klebsiella pneumoniae) that produce extended-spectrum $\beta$-lactamases (ESBLs) capable of hydrolyzing almost all cephalosporins except carbapenems has been reported worldwide (Pitout and Laupland, 2008). Previous studies by Hackman et al., (2013) in Accra 
established that extended-spectrum beta-lactamase (ESBL) producers were increasingly becoming a public health nuisance due to community acquired and nosocomial infections.

Treatment of these multiple drug-resistant organisms has proven to be a therapeutic challenge. ESBLproducing isolates pose serious public health, financial and logistics challenges because of the limited choice of antibiotics for the treatment of infections by ESBL producing isolates. The screening of natural products has been the source of innumerable therapeutic agents. Higher plants, as a source for new potential drugs is still largely unexplored and only a small percentage of them has been subjected to phytochemical investigation and the fractions submitted to pharmacological screening is very low (Saraswathy et al., 2011).

The leaves, stems and roots of Alchornea cordifolia (Schumach. and Thonn.) Müll. Arg are used as traditional medicine in many African countries for the management of gastrointestinal, respiratory and urinary tract infections as well as for the treatment of wounds (Siwe Noundou et al., 2016).

According to George et al. (2010), the potency of the A. cordifolia leaves extract could be attributed to various classes of compounds such as steroids, tri-terpenoids, phenols and polyphenols, alkaloids, flavonoids, anthraquinones, saponins and tannins, already known to be present in A. cordifolia leaves.

Siwe Noundou et al., (2016) isolated seven compounds from A. cordifolia with antibacterial activities namely stigmasterol, stigmasta-4,22-dien-3-one, friedelin, friedelane-3-one-28-al, 3-O-acetyl-aleuritolic acid , 3-Oacetyl-erythrodiol and methyl-3,4,5-trihydroxybenzoate (methyl gallate).

In this study, the antibacterial activity of ethanolic extract of Alchornea cordifolia leaf was tested against ESBL-producing $K$. pneumoniae. Phytochemical screening of the plants extract was performed to determine the various compounds. The study was based on the hypothesis that Alchornea cordifolia will possess phytochemical compounds that will have antimicrobial properties against ESBL-bacterial infections through in vitro analysis.

\subsection{Materials and Methods \\ 2.1 Study Site}

This research work was carried out at the Centre for Plant Medicine Research, Mampong-Akuapim in the Eastern Region of Ghana.

\subsection{Sampling of Test Plant Material and Extracts Preparation}

Thousand gram $(1000 \mathrm{~g})$ of the plant leaves were collected and authenticated at the herbarium at the Centre for Plant Medicine Research (CPMR), Mampong-Akuapim. The sampling was based on the assumption that the plant is healthy and uninfected. The plant parts were cut into pieces, air dried at $26 \pm 2{ }^{\circ} \mathrm{C}$ for ten days and milled into coarse powder with the aid of an electric blender.

\subsection{Ethanolic Extraction, Evaporation and Freeze Drying of Extracts}

Three hundred grams $(300 \mathrm{~g})$ of the powdered plant part was soaked in $2 \mathrm{~L}$ of $96 \%$ absolute ethanol for 72 hours with occasional stirring and was filtered through Wathman's No.1 filter paper. The filtrate was concentrated with the aid of a rotary evaporator and was freeze-dried using the freeze drying machine at a temperature and reduced pressure of $35^{\circ} \mathrm{C}$ and $100-80 \mathrm{hPa}$ respectively. The dried extract was stored under refrigeration condition $\left(4^{\circ} \mathrm{C}\right)$ until needed.

\subsection{Reconstitution of Serial Concentrations of the Crude Extract}

Eight hundred milligrams $(800 \mathrm{mg})$ of the dried crude extracts were disolved in $4 \mathrm{ml}$ of $5 \% \mathrm{v} / \mathrm{v}$ dimethyl sulphoxide (DMSO) to prepare $200 \mathrm{mg} / \mathrm{ml}$ concentration of the leaves extract. Subsequent concentrations of 100, 50, 25, and $12.5 \mathrm{mg} / \mathrm{ml}$ were achieved using the conventional two folds dilution technique.

\subsection{Preparation of Muellar Hinton Agar (MHA) as a Culture Media}

The culture media were prepared according to the manufacturers instruction. Thirty eight grams (38g) of the powder was suspended in $1000 \mathrm{ml}$ of demineralized water and heated to boil with agitation to completely dissolve the powder. The medium was then sterilized by autoclaving at $121^{\circ} \mathrm{C}$ for 15 minutes.

\subsection{Detection of ESBL-producing $K$. pneumoniae using Combined Disc Synergy Method}

MAST ID ${ }^{\mathrm{TM}}$ ESßL Detection Discs (Mast Group, UK) were used to screen and confirm the ESBL phenotypes. The MAST ID ${ }^{\mathrm{TM}}$ ESßL Detection Disks comprise of cefpodoxime $30 \mu \mathrm{g}$ disks, cefpodoxime $30 \mu \mathrm{g}+$ clavulanic acid $10 \mu \mathrm{g}$ disks; ceftazidime $30 \mu \mathrm{g}$ disks, ceftazidime $30 \mu \mathrm{g}+$ clavulanic acid $10 \mu \mathrm{g}$ disks and cefotaxime $30 \mu \mathrm{g}$ disks, cefotaxime $30 \mu \mathrm{g}+$ clavulanic acid 10 $\mu \mathrm{g}$ disks (Paterson and Bonomo, 2005).

Using a pure culture of the test organism, a suspension in distilled water equivalent in density to a McFarland 0.5 opacity standard was prepared. Using a sterile swab, the suspension was spread uniformly across the surface of Mueller-Hinton agar plate. Using a sterile forceps, one of each MAST ID ${ }^{\mathrm{TM}}$ ESßL Detection Disks was placed onto the inoculated medium ensuring that they were evenly spaced. The plates were incubated aerobically at 35- 
$37^{\circ} \mathrm{C}$ for $18-20$ hours. The diameter of any zones of inhibition that were observed were measured and recorded. The zone of inhibition for the cefpodoxime, ceftazidime and cefotaxime was compared to that of the cefpodoxime, ceftazidime and cefotaxime plus clavulanic acid combination disks. An increase in zone diameter of $=5 \mathrm{~mm}$ in the presence of clavulanic acid from any or all of the sets of MAST ID ${ }^{\mathrm{TM}} \mathrm{ES} ß \mathrm{~L}$ Detection Disks indicates the presence of ESBL in the test organism. isolates.

\subsection{Subculturing of Extended-spectrum Beta-lactamase Producing $K$. pneumoniae}

The test organism was subcultured onto Mueller Hinton agar plate and was incubated for 24 hours to obtain a pure culture and to ascertain the viability of the organism. At least four colonies from the pure culture were transfer into sterile peptone water using an inoculation needle and adjusted to turbidity equivalent to $0.5 \mathrm{McFarland}$ Standard.

\subsection{Antimicrobial Susceptibility Testing Using Agar Well-Diffusion Method}

Antimicrobial activity of the shrub extracts was assessed using the agar- well diffusion method. A $3 \mathrm{ml}$ inoculum was prepared in peptone water and adjusted to $0.5 \mathrm{McFarland}$ and uniformly spread on the MHA plate using the glass spreader. Wells $(6 \mathrm{~mm}$ diameter) were created in the plate using cork borer and $20 \mu \mathrm{l}$ of the shrub extract concentrations $(200 \mathrm{mg} / \mathrm{ml}-12.5 \mathrm{mg} / \mathrm{ml})$ were pipetted into the wells at their respective concentration. Amikacin $(30 \mu \mathrm{g} / \mathrm{ml})$ and colistin $(10 \mu \mathrm{g} / \mathrm{ml})$ disks were used as positive controls and $5 \% \mathrm{v} / \mathrm{v}$ DMSO and sterile distilled water (SDW) were used as the negative controls. They were allowed to diffuse at room temperature for 30 minutes and the plates were then incubated at $37^{\circ} \mathrm{C}$ for 24 hours. All experiments were carried out in triplicate.

After incubation, the diameter zone of inhibition (DZI) were measured and expressed in millimeters. DZI < $7 \mathrm{~mm}$ was considered inactive; $7-10 \mathrm{~mm}$ partially active; $11-16$ active and $>16$ very active as described by Junior and Zanil (2000).

\subsection{Determination of Minimum Inhibition Concentration (MIC)}

Hundred microlitres $(100 \mu \mathrm{l})$ of ethanol extract of the active shrub were added to $100 \mu 1$ of $5 \%$ DMSO in the first well of the 96-well microplate and mixed well with a micropipette; $100 \mu \mathrm{l}$ of this dilution was transferred to the next well in the column. This two-fold serial dilution was continued to obtain dilutions ranging from $10^{1}$ to $10^{10}$ with the aid of a micropipette. The final volume in each well was $100 \mu$ l. Solutions of a reference antibiotic amikacin $(30 \mu \mathrm{g} / \mathrm{ml})$ and colistin $(10 \mu \mathrm{g} / \mathrm{ml})$ were also serially diluted in different columns of the microplate as a positive control. The wells were inoculated with $5 \mu \mathrm{l}$ of microbial suspension of turbidity equivalent to 0.5 $\mathrm{McFarland}$ and incubated at $37^{\circ} \mathrm{C}$ for 24 hours. After incubation, $40 \mu \mathrm{l}$ of $0.2 \mathrm{mg} / \mathrm{ml} \mathrm{INT}$ (p-Iodonitrotetrazolium violet) dissolved in sterile distilled water was added to each of the wells. The microplates were examined after additional 30 to 120 minutes of incubation. Bacterial growth was indicated by a red colour of INT reduced to the formazan. The lowest concentration at which a decreased in the red colour is apparent compared to the next dilution was taken as the MIC value.

\subsection{Determination of Minimum Bactericidal Concentration (MBC)}

The MBC values were deduced from those wells with lowest concentrations at which no growth took place after culture for 24 hours of incubation. A small sample from each of those wells was transferred to fresh nutrient agar plates and was incubated overnight at $37^{\circ} \mathrm{C}$ and plates were examined for the presence or absence of living organisms. Plates with no microbial growth were regarded as the minimum bactericidal concentrations.

\subsection{Phytochemical Screening}

Phytochemical screening methods described by Fong et al., (1977) and Ciulei (1982) were used to screen the various extracts for the presence of saponins, reducing compounds, polyuronides, phenolic compounds, alkaloids, triterpenes, phytosterols, flavonoids and anthracenosides.

\subsection{RESULTS}

3.1 Susceptibility of Extended-spectrum Beta-lactamase Producing $K$. pneumoniae against Ethanolic Extract of Alchornea cordifolia.

The ethanolic extract of Christmas leaves showed varied zones of inhibition as in Table 1: 
Table 1: Susceptibility of Extended-spectrum Beta-lactamase-Producing $K$. pneumoniae to ethanolic extract of Alchornea cordifolia leaves

\begin{tabular}{|c|c|c|c|c|c|c|c|}
\hline Standards & & Diam & ones of inhi & ion (mm) & & & \\
\hline $\begin{array}{l}\text { Amikacin } \\
(30 \mu \mathrm{g} / \mathrm{ml})\end{array}$ & $\begin{array}{l}\text { Colistin } \\
(10 \mu \mathrm{g} / \mathrm{m})\end{array}$ & $\begin{array}{l}\text { SDW/ } \\
\text { DMSO }\end{array}$ & $200 \mathrm{mg} / \mathrm{ml}$ & $100 \mathrm{mg} / \mathrm{ml}$ & $\begin{array}{l}50 \\
\mathrm{mg} / \mathrm{m}\end{array}$ & $\begin{array}{l}25 \\
\mathrm{mg} / \mathrm{m}\end{array}$ & $\begin{array}{l}12.5 \\
\mathrm{mg} / \mathrm{ml}\end{array}$ \\
\hline $22.0 \pm 0.5$ & $17.0 \pm 0.5$ & 0.0 & $16.3 \pm 1.0$ & $13.7 \pm 0.5$ & $\begin{array}{l}11.9 \pm \\
1.3\end{array}$ & $\begin{array}{l}8.5 \\
2.5\end{array}$ & $0.0 \pm 0.0$ \\
\hline
\end{tabular}

Values are mean inhibition zone $(\mathrm{mm}) \pm \mathrm{S}$.D of three replicates

Minimum Inhibition Concentration (MIC) and Minimum Bactericidal Concentration (MBC)

The minimum inhibition concentration (MIC) and minimum bactericidal concentration (MBC) shown in Table 2 were determined using the 96 well microplate.

Table 2: MIC and MBC of ethanol leaves extracts of Alchornea cordifolia against ESBL-producing $K$. pneumoniae.

\begin{tabular}{lll} 
Plant extract & MIC $(\mathbf{m g} / \mathbf{m l})$ & MBC $(\mathbf{m g} / \mathbf{m l})$ \\
\hline Alchornea cordifolia & 3.13 & 3.13 \\
\hline
\end{tabular}

\subsection{Phytochemical Constituents}

The phytochemical constituents of the leaf extract were saponins, phenolic compounds, reducing sugars, polyuronoids and flavonoids as shown in Table 3. Previous work by Siwe Noundou et al., (2016) had identified the antibacterial compounds in $A$. cordifolia leaves and elucidated their chemical structure.

Table 3: Phytochemical constituents of Alchornea cordifolia leaves

\begin{tabular}{ll}
\hline Phytochemical & A. cordifolia \\
\hline Saponins & + \\
Phenolic compounds & - \\
Reducing sugars & + \\
Polyuronoids & - \\
Alkaloids & - \\
Triterpenes & - \\
Phytosterols & - \\
Flavonoids & + \\
Anthracenosides & - \\
\hline
\end{tabular}

Detected $=(+)$; Not Detected $=(-)$

\subsection{Discussion}

The outcome of this study suggested that ESBL-producing $K$. pneumoniae are sensitive to varied concentration $(50 \mathrm{mg} / \mathrm{ml}-200 \mathrm{mg} / \mathrm{ml})$ of the ethanolic extracts of Alchornea cordifolia leaves. More so, the ethanolic leaves extracts of Christmas bush leaves had MIC and MBC of $3.13 \mathrm{mg} / \mathrm{ml}$. This is an indication that the ethanolic extracts of Alchornea cordifolia leaves have significant antibacterial activity against multi-drug resistant K. pneumoniae. This may be because Alchornea cordifolia leaves possess rich phytochemicals such as saponins, reducing sugars and flavonoids.

This may be because Alchornea cordifolia leaves possess phytochemicals such as saponins, reducing sugars and flavonoids (George et al., 2010). Flavonoids are known to possess the antibacterial effect. According to Siwe Noundou et al., (2016) antibacterial compounds such as stigmasterol, stigmasta-4,22-dien-3-one, friedelin, friedelane-3-one-28-al, 3-O-acetyl-aleuritolic acid , 3- $O$-acetyl-erythrodiol and methyl-3,4,5-trihydroxybenzoate (methyl gallate)were isolated from Christmas bush. It could be that the extract used in this study may contain these compounds since they fall under flavonoids and the phytochemical screening of the test plant revealed that it contains flavonoids as shown in Table 1 . There might be other phytochemicals that were not determined in this study, which may be responsible for the antibacterial activity of the $A$. cordifolia leaves.

The activity of the standards (amikacin and colistin) used in this study as positive control corresponds with the results of Hackman et al., (2017) although amikacin $(30 \mu \mathrm{g} / \mathrm{ml})$ used in this study shows a higher diameter zone of inhibition. According to Junior and Zanil (2000) diameter zone of inhibition of 11-16 is considered active and $>16$ is considered very active. From the results, concentrations of the test plant ranging from $50 \mathrm{mg} / \mathrm{ml}-200$ $\mathrm{mg} / \mathrm{ml}$ showed active diameter zone of inhibition. From Table 2, Alchornea cordifolia had an MIC of $3.13 \mathrm{mg} / \mathrm{ml}$ with MBC of $3.13 \mathrm{mg} / \mathrm{ml}$ with percentage inhibition index of 2.94 . This indicate that Alchornea cordifolia is able to inhibit the growth of the ESBL-producing $K$. pneumoniae at the stated concentrations. 


\title{
5.0 Conclusion
}

The hypothesis for this study proved positive since the plant under study showed activity against the ESBLproducing $K$. pneumoniae. Ethanolic extracts of $A$. cordiofolia leaves is proving to be efficacious against multidrug resistant ESBL-producing $K$. pneumoniae, which a major cause urinary tract infections. Phytochemical screening of the leaves showed that it possesses flavonoids, saponins and reducing sugars, which is responsible for the antibacterial efficacy of the leaves extracts. This offers hope for the development of effective antibiotics for the treatment of multi-drug resistant systemic infections. Therefore, there is the need to determine the toxicological effect and perform clinical trials of the active antimicrobial compounds isolated in the leaves extracts of $A$. cordifolia.

\author{
Abbreviations \\ CPMR: Centre for Plant Medicine Research \\ DMSO: Dimethyl Sulphoxide \\ DZI: Diameter Zone of Inhibition \\ K. pneumoniae: Klebsiella pneumoniae \\ ESBL: Extended-spectrum beta-lactamase \\ INT: p-Iodonitrotetrazolium violet \\ MIC: Minimum Inhibitory Concentration \\ MBC: Minimum Bactericidal Concentration \\ MHA: Mueller Hinton Agar \\ SDW: Sterile Distilled Water

\section{Declarations \\ Ethics Approval and consent to participate} \\ Not applicable \\ Consent for publication \\ Not applicable \\ Availability of data and material
}

All data generated or analyzed during this study are included in this published article.

Competing interests

The authors declare that they have no competing interests.

Funding

Not Applicable

Authors' contributions

HKH designed the study. DB, BN, MA carried out the

experiment and collected the data. HKH, LA and REA performed the statistical analysis.

HKH, LA, BKA and REA interpreted the clinical data. All authors' read and approved the

final version of the manuscript.

\section{Acknowledgment}

The authors acknowledge the logistical support by Centre for Plant Medicine Research

\section{References}

Ciulei I (1982). Methodology for analysis of vegetable drugs. Practical Manuals on Industrial Utilization of Medicinal and Aromatic plants. Edited by the Ministry of Chemical Industry, Bucharest: 73.

Flores-Mireles AL, Walker JN, Caparon M, Hultgren SJ (2015). Urinary tract infections: epidemiology, mechanisms of infection and treatment options. Nature Reviews. Microbiology, 13 (5): 26984. doi: $10.1038 /$ nrmicro3432.

Fong EHS, Tin-Wa M, Farnworth NR, Dobberstein RH (1977). Phytochemical Screening Methods. Department of Pharmacognosy and Pharmacology. College of Pharmacy, University of Illinois, USA. pp. 15-20.

George NJ, Obot IB, Akot AN, Apkan AE, Obi-Egbedi NO (2010). Phytochemical and antimicrobial properties of leaves of Alchornea cordifolia. E-J. Chem., 7(3):1071-1079.

Hackman HK, Osei-Adjei G, Ameko E, Kutsanedzie F, Gordon A, Laryea E, Quaye S, Anison L, Brown CA, Twum-Danso K. (2013). Phenotypic Determination and Antimicrobial Resistance Profile of Extended Spectrum Beta-lactamases in Klebsiella pneumoniae and Klebsiella pneumoniae in Accra, Ghana. Journal of Natural Sciences Research, 3(12): 75.

Hackman KH, Arhin ER, Gordon A, Mensah BNS (2017). Emergence of Carbapenem-resistant Enterobacteriaceae among Extended-spectrum Beta-lactamase Producers in Accra, Ghana. Journal of Natural Sciences Research, 7(1): 4-5. 
Junior A, Zanil C (2000). Biological screening of Brazilian medicinal plants. Brazilian Journal of Science, 5.

Nordmann P, Naas T, Laurent P (2011). Global spread of carbapenemase-producing Enterobacteriaceae. Emerging infectious Diseases, 17(10):1791.

Paterson DL, Bonomo RA (2005). Extended-spectrum ß-lactamases: a clinical update. Clinical Microbiology Reviews, 18(4): 657-686.

Pitout JD, Laupland KB (2008). Extended-spectrum $\beta$-lactamase-producing Enterobacteriaceae: an emerging public-health concern. Lancet Infect Dis., 8(3):159-166.

Salvatore S, Salvatore S, Cattoni E, Siesto G, Serati M, Sorice P, Torella M (2011). Urinary tract infections in women. European Journal of Obstetrics, Gynecology, and Reproductive Biology, 156 (2): 1316. doi:10.1016/j.ejogrb.2011.01.028.

Saraswathy A, Gunalan G, Krishnamurthy V (2011). Antimicrobial Activity of Medicinal Plant Bauhinia variegate Linn. International Journal of Pharmacy and Biological Sciences, 1:400.

Siwe Noundou X, Krause RWM, van Vuuren SF, Ndinteh DT, Olivier DK (2016). Antibacterial effects of Alchornea cordifolia (Schumach. \& Thonn.) Müll. Arg extracts and compounds on gastrointestinal, skin, respiratory and urinary tract pathogens. Journal of Ethnopharmacology, 179:76-82 . 